\title{
EDITORIAL
}

\section{National Health Insurance - a Bill too far?}

The Deputy Minister of Health, Dr J Phaahla, opened our $22^{\text {nd }}$ National Family Practitioners Conference $^{1}$ with a plenary address and discussion on National Health Insurance (NHI). The NHI Bill ${ }^{2}$ is now before Parliament and there is much debate in the media regarding its pros and cons. Much of the media attention is skeptical and

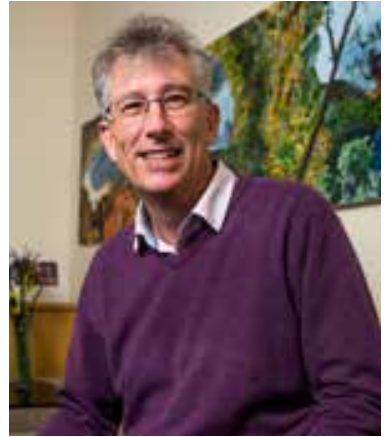
even derogatory with headlines such as "why South Africa's plans for universal healthcare are pie in the sky".

The Deputy Minister's position in his plenary address was that the government have taken a decision to implement $\mathrm{NHI}$ and that the discourse is no longer about whether to do so, but about how to do so. He reiterated the argument for change due to the enormous inequities in our provision of health care and use of resources in South Africa. He explained that the government welcomes constructive criticism of the Bill in terms of how to implement NHI better and there will be an opportunity for public comment.

Universal health coverage is a core component of the World Health Organization's strategies to achieve the sustainable development goals. ${ }^{4}$ Universal health coverage implies that essential health services should be available, accessible and of a high quality; and is not just about a model of financing health care. Financial risk protection is however also central to universal health coverage and $\mathrm{NHI}$ is a way of achieving this. NHI will first be implemented in primary health care.

The essential ingredients of $\mathrm{NHI}$ include access for all to a defined package of care with no payment at the point of use. ${ }^{2}$ Payment for health care would come from a combination of payroll taxes, personal income tax, reallocation of medical scheme tax credits and other taxes. Funds would be used to purchase the package of care from accredited providers, whether in the public or private sector. Everyone would need to register with a primary care provider as payment would be based on a capitation model and not a fee for service.

Research conducted with private GPs in the Western ${ }^{5}$ and Eastern Cape $^{6}$ suggest that those serving poorer and rural communities are supportive of the values and principles of $\mathrm{NHI}$ and see the benefits for their patients. Services would be more comprehensive and GPs would only need to deal with one purchaser. At the same time GPs had significant concerns about the capacity of government to re-engineer the system and efficiently implement $\mathrm{NHI}$, particularly the ability to remunerate GPs efficiently. GPs were also frustrated by the lack of specific information with regard to registration of patients and accreditation and worried about the implications for solo GPs.
At the conference Dr Paahla explained that solo GPs would be able to network with other health professionals to provide the package of care if necessary.

At the conference, delegates also raised concerns regarding possible corruption with the pooling of such large sums of money and the independence of $\mathrm{NHI}$ governance from political patronage. The Deputy Minister attempted to reassure the delegates that the Minister would not be able to use NHI for such patronage. Dr Nicholas Crisp who was recently appointed to head up the NHI office has also commented that the hypervigilance of civil society at this time would make such a scenario unlikely.

The Presidential Health Compact $^{8}$ that was signed by the South African Medical Association (to which the SA Academy of Family Physicians is affiliated) is highly supportive of the implementation of $\mathrm{NHI}$, but likewise highlights issues that must be addressed. These include engagement with the public and professionals to ensure people understand what $\mathrm{NHI}$ is all about. New human resources for health policy must be agreed to deliver on $\mathrm{NHI}$ going forward and all infrastructure should meet the requirements of the Office of Health Standards Compliance.

I communicated to the Deputy Minister that the South African Academy of Family Physicians was committed to supportive and constructive interaction with government on the implementation of NHI. We plan to give all our members the opportunity to give such constructive feedback and to collate a response from the Academy to the new NHI Bill.

\section{Prof Bob Mash}

President: South African Academy of Family Physicians

\section{References:}

1. 22nd National Family Practitioners Conference: The primary health care team: Roles and alignment to the ideals of the National Health Insurance. Available from http:// www.saafp.org/conferences/index.php/ANFPC/2019 [Accessed 3rd September].

2. Department of Health. National Health Insurance Bill, 2018. Government Gazette 21 June 2018 (No. 41725) Available at https://www.gov.za/sites/default/files/gcis document/201908/national-health-insurance-bill-b-11-2019.pdf [Accessed 19th September 2019].

3. Van den Heever A. Why South Africa's plans for universal healthcare are pie in the sky. Available from https://theconversation.com/why-south-africas-plans-foruniversal-healthcare-are-pie-in-the-sky-121992 [Accessed 3rd September 2019].

4. Leave no one behind: strengthening health systems for UHC and the SDGs in Africa. Brazzaville: WHO Regional Office for Africa; 2017. Available from https:// www.afro.who.int/sites/default/files/2017-12/UHC\%20framework_eng_2017-1127_small.pdf [Accessed 3rd September 2019].

5. Mathew $S$, Mash R. Exploring the beliefs and attitudes of private general practitioners towards national health insurance in Cape Town, South Africa. Afr J Prm Health Care Fam Med. 2019, In Press.

6. Gaqavu M, Mash R. The perceptions of general practitioners on National Health Insurance in Chris Hani district, Eastern Cape, South Africa, South African Family Practice,2019: DOI: 10.1080/20786190.2019.1596665.

7. Heyward M, Nicholas Crisp: A man on a mission to make NHI work. Available from https://www.dailymaverick.co.za/article/2019-08-19-nicholas-crisp-a-man-on-amission-to-make-nhi-work/ [Accessed 3rd September 2019].

8. South African Government: Strengthening the South African health system towards an integrated and unified health system, Presidential Health Compact, 25 July 2019. Available from https://www.hfassociation.co.za/images/docs/Presidential_Health_Compact.pdf [Accessed 3rd September 2019]. 